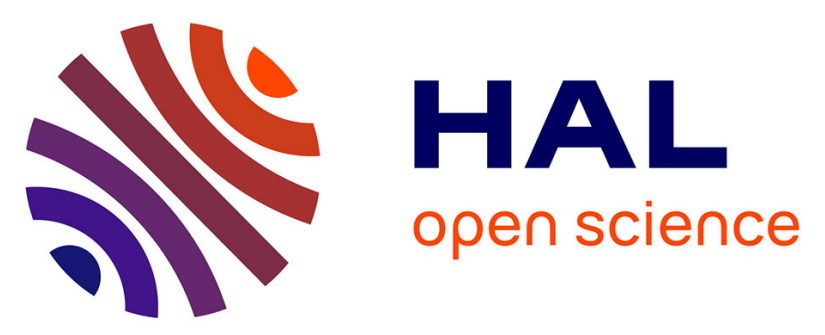

\title{
Designing the safety of healthcare. Participation of ergonomics to the design of cooperative systems in radiotherapy
}

Maria Isabel Munoz, Nadia Bouldi, Flore Barcellini, Adelaide Nascimento

\section{- To cite this version:}

Maria Isabel Munoz, Nadia Bouldi, Flore Barcellini, Adelaide Nascimento. Designing the safety of healthcare. Participation of ergonomics to the design of cooperative systems in radiotherapy. 18th World Congress on Ergonomics, International Ergonomics Association, Feb 2012, Recife, Brazil. 10 p. halshs-00756293

\section{HAL Id: halshs-00756293 \\ https://shs.hal.science/halshs-00756293}

Submitted on 22 Nov 2012

HAL is a multi-disciplinary open access archive for the deposit and dissemination of scientific research documents, whether they are published or not. The documents may come from teaching and research institutions in France or abroad, or from public or private research centers.
L'archive ouverte pluridisciplinaire HAL, est destinée au dépôt et à la diffusion de documents scientifiques de niveau recherche, publiés ou non, émanant des établissements d'enseignement et de recherche français ou étrangers, des laboratoires publics ou privés. 


\title{
Laboratoire d'Ergonomie
}

\section{Centre de Recherche sur le Travail et le Développement}

Conservatoire national des arts et métiers - Paris

\author{
Maria Isabel Munoz *, Nadia Bouldi, Flore Barcellini \& \\ Adelaide Nascimento
}

\section{Designing the safety of healthcare. Participation of ergonomics to the design of cooperative systems in radiotherapy}

\begin{abstract}
This communication deals with the involvement of ergonomists in a researchaction design process of a software platform in radiotherapy. The goal of the design project is to enhance patient safety by designing a workflow software that supports cooperation between professionals producing treatment in radiotherapy. The general framework of our approach is the ergonomics management of a design process, which is based in activity analysis and grounded in participatory design. Two fields are concerned by the present action: a design environment which is a participatory design process that involves software designers, caregivers as future users and ergonomists; and a reference real work setting in radiotherapy. Observations, semi-structured interviews and participatory workshops allow the characterization of activity in radiotherapy dealing with uses of cooperative tools, sources of variability and non-ruled strategies to manage the variability of the situations. This production of knowledge about work searches to enhance the articulation between technocentric and anthropocentric approaches, and helps in clarifying design requirements. An issue of this research-action is to develop a framework to define the parameters of the workflow tool, and the conditions of its deployment.
\end{abstract}

Keywords: Patient safety, Radiotherapical care, CSCW, Design, Participatory process.

2012

Réf. : Munoz, M.I., Bouldi, N., Barcellini F. \& Nascimento, A. (2012). Designing the safety of healthcare. Participation of ergonomics to the design of cooperative systems in radiotherapy. 18th World Congress on Ergonomics (International Ergonomics Association), February 11-16, Recife, Brazil. In: Work, 41(Supplement 1), 790-796. 


\title{
Designing the safety of healthcare. Participation of ergonomics to the design of cooperative systems in radiotherapy
}

\author{
Maria Isabel Munoz *, Nadia Bouldi, Flore Barcellini \& Adelaide Nascimento \\ Ergonomics Laboratory. Research Center on work Development (CRTD) - Conservatoire National des \\ Arts et Métiers, 41 rue Gay Lussac, 75005 Paris, France
}

\section{Introduction}

This communication presents the implication of ergonomics researchers in an action-research design project. The computer environment to be designed aims at providing a technological answer to the safety of care in radiotherapy.

Radiotherapy is a medical specialty that uses ionizing radiation to treat cancer. This disease is the second cause of death in Europe and the United Sates. About $60 \%$ patients with cancer are treated by radiotherapy.

The present research addresses two issues:

- a pragmatic issue dealing with contribution of ergonomics to a design process regarding the production of a safe radiotherapy treatment and its potential assistance through computer-supported environments (a workflow software).

- a theoretical issue dealing with the participation of ergonomics in the design of work situations promoting patient safety by taking into account computer supported environment as a key element that would have to support cooperation between operators and production of ruled and non-ruled safety.

\section{Context of the research}

\subsection{The objective of the project: designing a software in radiotherapy}

The objective of the project is to design a platform that supports the process of elaboration of a radiotherapy care. Its aim is to promote the quality and the safety of care. The platform will be composed by several computer tools: a computerized patient file, a workflow management system, a software for checking the total dose of radiation transmitted to the patient and a software evaluating risks of developing a second cancer related to the treatment. Some of these tools concern one type of professionals of the chain, but only the workflow management system concerns all the operators of the chain.

\section{A partnership involving eleven entities}

The project is a four years cooperative project financed by government subsidies, which brings together eleven organizations and SMEs from different areas: three editors of medical software, five hospitals and three research laboratories in scientific computing, epidemiology and ergonomics. The project is conventionally organized into eight lots referring to the design of a particular software of the

\footnotetext{
*Corresponding author. E-mail: mariaisabel.munoz@cnam.fr
} 
whole platform and to the implementation of particular studies to clinic validation. One lot is dedicated to global coordination of the project.

This communication presents the design project of the second lot, which goal is to design a workflow tool. This lot involves a software editor company, the ergonomists team and the major cancer research hospital in Paris.

\subsection{Radiotherapical treatment as an outcome of a cooperative activity}

Radiation treatment is distributed in time, space and between different care providers. Development and administration of a safe radiotherapy treatment need the involvement of at least four types of professionals. Radiographers, radiation oncologists, medical physicists, dosimetrists provide their own area of expertise to the implementation of radiotherapeutic treatment. Altogether, these professionals design a safe radiotherapeuthic defined by three criterions: the dose to be delivered, the tumor area to be irradiated and the deadline for applying the treatment [12]. Deviation concerning one of three parameters can cause negative effects to the patient's healthy tissues or reduce the efficacy of the treatment. Thus, radiotherapy may be regarded as the outcome of a cooperative activity, in which all the professionals are in charge of the safety of care.

In order to support cooperative work, the treatment process tends to be automated through computing environments. In our context, the considered tool to be designed concerned the management of workflow data in radiotherapy services.

\section{Workflow management tool supporting the cooperative activity in radiotherapy}

A workflow system is a key tool for computer-supported cooperation. Workflow describes and automates some procedural steps and exchanges of data that have to be performed by professionals such as transition between steps - or provide professionals with information they need to perform their tasks. The aim of workflow tools is to support the progress in the production of treatments between different phases of the process.

In radiotherapy, the goal of such tools is to control and to follow up the elaboration of a treatment. At the end of each phase, the validation of the concerned actor allows the system to advance to the next step. Information is automatically transferred from a computerized workstation to another in order to prevent the risk of error associated with manual entry of treatment parameters [17]. Thus, the designed workflow tool might support the flow (the advancement of patient files) among the different steps of the process in radiotherapy.

\section{Research issues and strategy}

\subsection{Issues in the design of tools assisting cooperation in radiotherapy}

In general, tools that support cooperation, including workflow tools, are designed to improve coordination between several operators. In radiotherapy, these tools are used to promote the quality of the care and to prevent the risk of errors attributed to coordination problems [17]. Indeed, one risk is that this kind of tool supports only the prescribed process - or ruled safety - impeding the implementation of a non-ruled safety, of non-prescribed actions, in the daily operator's activity [11][16]. We assume that this non-ruled safety may require a system flexible enough, to support the operators' daily activities, who have to cope with the diversity and the variability of daily production $[5][7]$. 


\subsection{Research objectives}

In the context of the participation in a design project of a software tool in radiotherapy that supports cooperative work, the goal is to enrich the technocentric and ruled-safety initial approach with an approach related to computer Supported Cooperative Work (CSCW)[18]. Our point is to enrich the design process with knowledge about work issues from analyses of real work and from workshops meetings. Besides, we aim at model the process and to identify the tools used.

To achieve our objectives, we aim at highlighting the variability of the daily situations that operators have to cope with and the implementation of non-ruled safety strategies. Those data could lead to definition and implementation of the workflow tool in order to enable it to support the production of safe care. The formalization and transmission of these data to the software editors might contribute to the definition of the workflow tool by aligning needs in radiotherapy, and possibilities and technical limitations of the tool.

\subsection{An approach grounded in participatory design}

The general framework of our approach is the ergonomics management of a design process, which is activity-based and grounded in participatory design and ergonomics [6][8]. In this perspective, key issues for the performance of the process are: social construction of the participatory design process [7] and taking into account probable future activity [2].

The goal of the social construction of the participatory design process is to enable the articulation of different actors' positioning and the implication of all partners in the process. For this, the role of each partner should be explicit.

To guide design choices, it is essential to approach the probable future activity of users, which means trying to identify non nominal situations that may occur in the work settings. To be able to anticipate the activity that would take place in the future situation, the probable future activity has to be elaborated on the basis of work analysis in real work settings. A work situation is anything but stable. Operators face a wide range of situations in their daily work. Some situations are planned by the organization, and others are unexpected situations. Thus, certain situations are recognized and its management is provided by the organization through technical and organizational measures. Some examples of diversity of situations that professionals have to deal with in radiotherapy are: different anatomical areas to be treated and different kind of irradiation techniques. But some situations that operators have to manage are beyond the scope of the operations prescribed. The operator must manage them though his/her skills. Some examples of situations of variability are: management of a patient with a disability, a schedule in situation of delay, an incomplete patient file, a failure of a machine [6][9].

In order to approach the probable future activity, analyses of real work settings have to outline variability and diversity of situations that operators have to cope with to achieve the production [7]. Moreover, the production of knowledge about work in workshops might enhance the knowledge about probable future activity.

\section{Method}

\subsection{Fields of research}

This research is developed in two fields: 
- the radiotherapy department of a Parisian institute which is concerned by work analysis. This center is involved in research about mechanisms of emergence and progression of cancer, and in treatment of patients. The technical equipment of the radiotherapy service includes two simulation stations and seven treatment stations. Each treatment station receives from 10 to 40 patients per day. Nearly 80 professionals from different specialties work on this technical platform;

- the design situations in the project involving the software editors and professionals in radiotherapy.

\subsection{Social construction of the intervention}

In both fields, social construction of participatory design process is achieved to establish the participatory process.

In the design situations, ergonomics approach has been exposed to all partners (designers and some users' representants) in five workshops. The topics of the meetings have been: the design process as approached in ergonomics, the findings form previous researches in radiotherapy, the tools already developed by software editors as well as internal coordination of the lot.

A first qualitative coding of these workshops have been conducted to identify issues that have to be taken into account for the next steps of the process, for instance the technocentric positioning of stakeholders about the design process, or their representation of determining factors of safety.

In the radiotherapy department, we conducted three presentations of ergonomics and its implications with safety based on the results from activity analysis.

\subsection{Highlighting the probable future activity in radiotherapy chain}

This phase of the action-research concerned the real work analysis. It was structured around three themes: understanding the process in radiotherapy, identifying the variability factors in the chain of the radiotherapy treatment and highlighting management methods of these factors by professionals.

\subsubsection{Analysing a reference real work situation}

In order to understand the process in radiotherapy, an ergonomic analysis of work is performed in the radiotherapy department of the field. This department was chosen as an existing reference situation because it has deployed its own «home-made» workflow management tool. We assume that characterizing how work is performed in this center, with this workflow tool, could be insightful to understand how the activity could be in a radiotherapy center with a new workflow tool.

We carried out an activity analysis of each professional to understand the process. This analysis is composed by: 100 hours of observations regarding the particularities of the activity of each care provider and the supports of cooperation used, 17 hours of systematic analyse of the uses of tools by operators, 10 semi-structured interviews about communications between the simulation step and the last step in the treatment chain.

\subsubsection{Producing collectively knowledge about work}

In order to complete the knowledge about work, participatory workshops are conducted. The goal is to highlight the variability of different phases of the treatment chain and the operator's exigencies at work.

Four design workshops have been organised involving care providers, software designers and ergonomists. The issues discussed at the workshops are: (1) definition of the different stages of the 
process (2) validation of the model of the radiotherapy chain realised by the ergonomics team (c.f. Fig 1), (3) focus on different phases of the chain of radiotherapy treatment: medical prescription, its determinants and parameters; planning sessions, anatomical data collection and its links with the different situations of variability (related to the patient, to the technical equipment) and solutions implemented by professionals to deal with them (management of urgencies, etc). The workshops have been recorded and qualitatively analysed to identify sources of variability of de process and the operator's needs.

\section{Results}

Our findings are organized in three areas: the approach of the stakeholders situations producing safety, the draft of the probable future activity from the analysis of a reference situation and the collective production of knowledge about work in radiotherapy.

\subsection{An initial technocentric perspective to guarantee the safety of the treatment}

The first qualitative analysis of workshops revealed that for stakeholders in the design project, patient safety is supposed to be reached thanks to an increase of control and automation of each situation in radiotherapy. Design actors were initially centred on errors prevention in treatment production in an over-prescribed and technocentric perspective of safety production in healthcare.

\subsection{Characterizing the reference real work}

\section{Modelling the process}

The study in the radiotherapy platform, our field of analysis, allows us to model the treatment chain. The chain to produce a radiotherapeuthic care has 17 sequential steps [3]. A simplified model is presented in Figure 1. The process (the flow) in radiotherapy begins at the multidisciplinary therapeutic decision workshop (RCP), which allows the schedule of the treatment sessions. The anatomical collection of data realized by radiographers is essential to radiation oncologist to define precisely the target area. After this phase, the calculation of the irradiation beams by dosimetrist complete the definition of the treatment. Next, real feasibility of the treatment is checked-out by radiographers in the test session (J0) and by a test with artifacts (phantoms) before the treatment sessions.

\section{Mediation in radiotherapy}

Cooperation throughout these steps is mediated by more than 16 tools, such as paper patients files, computer media, tools related to the patient and also communication and verbal exchanges. In a previous research [12] we identified the main uses of this multiplicity of tools: transmitting information to conceive the treatments and updating the collective contextual information.

\section{Identification of exchanges that participate of non-ruled safety}

Besides the tools, informal exchanges have been observed. Those exchanges are strategies that contribute to the elaboration of a safe treatment. For example, between the simulation step and the treatment step, non-ruled communications in addition to prescribed information in the patient paper file, let to define unusual position of the patient on the treatment table [13]. Non prescribed exchanges have also been observed in order to mobilize the actors of the chain to avoid delays in the treatment of a patient file [13][14]. 


\section{Identification of diversity and variability sources}

For the moment, we identified that sources of diversity in implementing a treatment are related to the type of treatment, i.e. the level of complexity of treatment impacts the number of steps and the duration of the preparation of the treatment (form 5 to 21 days depending on the technique). The sources of diversity are also related to the location of the tumor which impacts the position of the patient on the treatment table, a parameter that is collectively defined [13].

Concerning variability, four elements of variability are identified: information gaps (incomplete files, and unclear medical prescriptions), emergency treatments, failures of machines. Finally, the patient is also a source of variability due, in particular to: personal constraints, difficulties to cooperate (child, non-French speaker patient), an evolution of his/her morphology or his/her illness during treatment and negative reactions to the treatment (burning, difficulty in swallowing). These situations may impact the implementation of the process: the treatment can be reported, modified, or some phases have to be performed again [3].

\subsection{Producing collectively knowledge about work}

Analysis of the workshops reveals that three parameters can define the evolution of the real data flow that might to be supported by the workflow tool. On the basis of the analysis of the existing situation and from the study of the content of work meetings, we identified three parameters of the evolution of patient files flow in radiotherapy, that have to be followed to determine the functionalities of the workflow tool: the sequence (order of steps and presence or not of steps), the temporality (plan in the time, length of steps) and the progression (advancement to the next step). Our positioning is to analyze the real patient file evolution to set the configuration of the tool.

\subsection{Formalizing and transmitting to the software editors the users' requirements}

Transmission of the results of analyses is an issue for ergonomics. Thus, in order to create working documents to the participants to the workshops, addressed in particular to the software editors, we choose to formalize the essence of our analysis into two documents in order to: transmit the model of the existing situation, redefine the goals of the tool and sum up the users' requirements.

The first document describes the process in radiotherapy: the model of the steps in treatment chain (c.f. Fig 1), the actors involved and the tools used. This document presents the results of our analysis that allow us to present the workflow tool from a tool just for transmitting data, to a tool that aims coordination within the group.

The second document sums up the users' requirements that the tool might support. We choose to present each step of the project focusing on each professional involved at each step: objectives pursued, tools mobilized, necessary data and produced data.

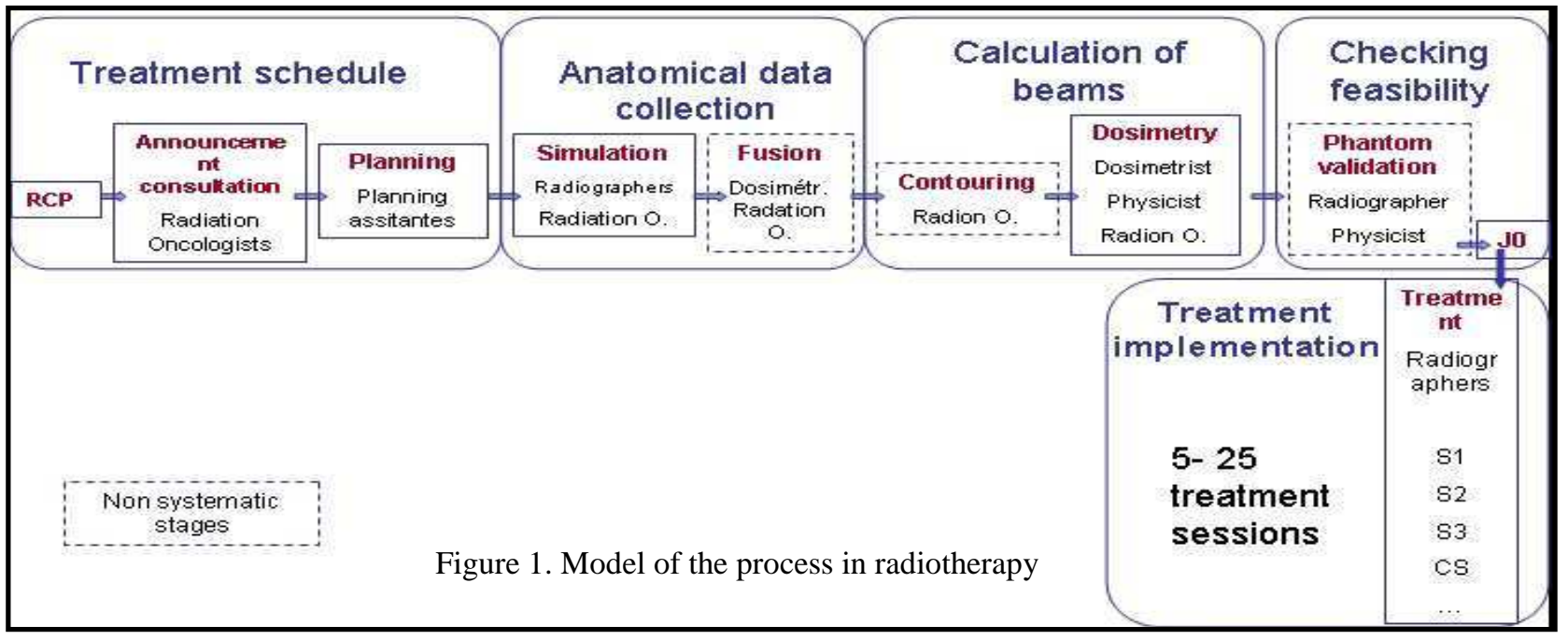




\section{Discussion}

\subsection{Redefinition of requirements of the workflow tool}

The designed workflow tool has been initially thought just to support the exchanges of data. But the results of our research help in allocating more functionalities to the tool: the initial approach of the whole design project is a technocentric one. Such a perspective is limited to the prescribed model of the treatment chain. The workflow software is no more just a software that automates the exchanges of data but it must support the update of the collective contextual information that helps operators to produce safety copping with daily variability [12][14].

\subsection{Taking into account non-ruled safety}

The findings of our researches and the participatory process permit to take into account non prescribed situations and the daily non-ruled safety performed by professionals, i.e. strategies adopted by operators to maintain a safe production by an informal kind of safety management [14]. This non ruled safety allows the operators to anticipate error situations [1]. Integrated in the future system, this whole approach would provide an anthropocentric point of view about safety issues to the design process. Moreover, our findings are consistent with the works in CSCW, stressing that tools for cooperation must support the coordination between operators and the construction of the collective situation awareness [18]. A review of these aspects of the reference situation and the management of the participatory process may help in designing a new work situation promoting patient safety [4][10].

\subsection{Towards a framework to implement the workflow tool.}

Once we identified these strategies, an issue is to implement the workflow tool in different work settings. From the exchanges in the workshops, it appears that the workflow system, must present a real important degree of flexibility. Over a period of several months (depending on size of service and time spent in the process) the workflow tool should be customized depending on the characteristics of the radiotherapy service.

Thus, technical choices must allow a large initial flexibility. The question raised is: in which way the implementation of the workflow tool may be followed up in different services in order to assist the production of safety in each specific situation? An issue must be to identify the items that have to be analyzed in the work situation where a future workflow tool would be implanted and its repercussions on the definition of parameters of the workflow tool.

In order to define the protocols and the level of automation of the workflow tool, the objective is to identify variability, diversity, formal and informal practices of each radiotherapy service,. Thus, the flexibility of the tool can be managed into its initial configuration and deployment in order to support the formal and informal local safety practices.

Other elements need to be defined: steps to be automated or not, protocols, validations, rights of access or data submitted to the various professionals at each stage. These parameters might be thought within the radiotherapy service in order to conduct the definition of workflow tool before its deployment. 


\section{Perspectives}

The main objective is to develop a framework for the definition of the tool and its deployment in a specific technical platform. According to our findings several issues emerge: in the pragmatic perspective, an issue is to propose software specifications to develop a software workflow tool that may: enable cognitive and operative synchronization, permit the transmission of information about variability factors, be adapted to the different professions and support formal and informal local safety strategies. A point to develop is taking into account different sources of variability and diversity of situations and its non-prescribed management by the actors. We have started to do this but we can improve the work by considering a wider range of variability and diversity of situations and by improving the transmission of our findings to software editors to make sure that they could appropriated them.

Another point to develop is the identification of categories of invariant factors in radiotherapical work settings that might assist the parameterization of the workflow tool in each situation, according to three parameters that define the flow: sequence, temporality and progression of files in the treatment chain. Moreover, a research perspective is to try to develop the following questions: what is to handle the design process of a system which an essential part of the production is patient safety? or, what does participate in the design of patient safety system?

\section{Acknowledgement}

This research takes place in the frame of the INSPIRA project, which is funded by OSEO and the pole MEDICEN.

\section{References}

[1] Amalberti, R. (2007). Ultrasécurité.Une épée de Damoclès pour les hautes technologies. Sciences à risques. Les dossiers de la recherche $n^{\circ} 26,74-81$.

[2] Beguin, P., Colas, R., Maugey, B., Renzeau, F. \& Amalberti, R. (1999). Modèles et méthodes d'implication des utilisateurs dans le processus de conception. Journées cognition et conception, «Place de l'utilisateur final dans le processus de conception » Lyon 1999.

[3] Bouldi, N., Munoz, M.I., Barcellini, F. \& Nascimento, A. (2011). Participation à la conception d'une plateforme informatique pour la production collective d'un soin sûr en radiothérapie. In conférence SELF 2011, Paris,France.

[4] Carayon, P., Alvarado, C.J. \& Schoofs (2007). Work design and patient safety. Theoretical Issues in Ergonomics Science, vol 8-5, 395-428.

[5] Daniellou, F. (2004). L'ergonomie dans la conduite de projets de conception de systèmes de travail, In : P. Falzon(Ed), Ergonomie. Paris : PUF.

[6] Daniellou, F., Béguin, P. (2004). Méthodologie de l'action ergonomique : approches du travail réel, In : P. Falzon(Ed), Ergonomie. Paris : PUF. [7] Daniellou, F. (2007). Simulating future work activity is not only a way of improving workstation design. @ctivités, 4, p.84-90. http://www.activites.org/v4n2/v4n2.pdf

[8] Garrigou, A., Daniellou, F., Carballeda, G., Ruaud,S. (1995). Activity analysis in participatory design and analysis of participatory design activity. IJIE, 15(5), 311-327.

[9] Guérin, F., Laville,A., Daniellou, F., Duraffourtg, J . \& Kerguelen A. (2006). Comprendre le travail pour le transformer. Lyon : ANACT.

[10] Hollnagel, E. (2009). The ETTO Principle : Efficiency - Thoroughness Trade - Off. Why things that go right sometimes go wrong ?. Farnham (United Kingdom): Ashgate.

[10] Morel, G., Amalberti, R. \& Chauvin, C. (2008). How good micro/macro ergonomics may improve resilience, but not necessarily safety. Safety Science, 47(2), 285-294.

[12] Munoz, M.I., Barcellini F., Mollo, V. (2010). Produire la sécurité des soins en radiothérapie : supports à la coopération dans le collectif de travail. In conference SELF 2010, Liège, Belgique. 
[13] Munoz, M.I., Barcellini, F \& Mollo,V. (2011). Collective elaboration of care for safety in radiotherapy: Cooperative management of patient variability. In conference HEPS (Healthcare ergonomics and patient safety). Oviedo, Spain, 22-24 juin 2011.

[14] Munoz, M.I., Mollo, V., Barcellini, F. Nascimento, A. (2011). Design of a safe computer-supported cooperative environment in radiotherapy: exploratory identification of cooperation strategies. In conférence ECCE 2011 (European Conference on Cognitive Ergonomics), Rostock, Germany.

[15] Nascimento, A. \& Falzon, P. (2008). Risk management in Radiotherapy, in L.Sznelwar, F. Mascia and U.Montedo (Eds.) Human Factors Organizational Design and Management, IX, Sao Paulo, 19-21mars 2008.

[16] Nascimento, A. (2009). Produire la santé, produire la sécurité. Développer une culture de sécurité en radiothérapie. Thèse de doctorat en ergonomie, CNAM, Paris.

[17] Rosenwald, J.C. (2002). Sécurité en radiothérapie: le contrôle de logiciels et des systèmes informatiques. Cancer/Radiotherapy, 6 (2002) Suppl 1: 180-186.

[18] Schmidt, K. (1994). Cooperative work and its articulation: Requirements for computer support. Le Travail Humain, 57(4), 345-366.

[19] Schmidt, K.(2002). The Problem with 'Awareness', Computer Supported Cooperative Work 11:285-298. 